\title{
Evaluating the utility of computed tomography of the chest for gastric cancer staging
}

\author{
Jordan Nostedt, MD \\ Lindsay Gibson-Brokop, BSc \\ Sunita Ghosh, PHD \\ Michael Seidler, MD \\ Michael McCall, MD, PHD \\ Daniel Schiller, MD, MSc
}

A preliminary abstract of this work was presented at the Canadian Surgery Forum 2018, Sept. 13-15, 2018, St. John's, Nfld.

Accepted June 27, 2019

\section{Correspondence to:}

\section{Schiller}

Community Services Centre, Rm 204

10240 Kingsway Ave

Edmonton, $\mathrm{AB}$ T5H $3 \mathrm{~V} 9$

ds9@ualberta.ca

DOI: $10.1503 /$ cjs.000319
Background: International guidelines recommend routine computed tomography (CT) of the chest for gastric cancer staging. In Asian countries, where the incidence of pulmonary metastases is less than $1 \%$, some guidelines recommend chest CT only for gastroesophageal junction cancers. If the incidence of pulmonary metastases is also low in Canada, routine chest CT may not be beneficial.

Methods: We performed a retrospective review of patients in northern Alberta with newly diagnosed gastric cancer from January 2010 to July 2016. The primary aim of the study was to determine the incidence of pulmonary metastases at the time of diagnosis in this population. A secondary aim was to identify potential predictors of pulmonary metastases. We reviewed CT reports for pulmonary metastases. Imaging data also included liver metastases, abdominal lymphadenopathy $(>1 \mathrm{~cm})$, ascites and omental or peritoneal nodules. Other data recorded were age, sex, primary tumour location, histologic type and tumour grade.

Results: Four hundred and sixty-two patients (311 men, 151 women) were included in the analysis. Pulmonary metastases were identified in 25 patients $(5.4 \%)$ overall and in 11 of 299 patients $(3.7 \%)$ whose primary cancer was not in the cardia. On univariate analysis the presence of liver metastases (odds ratio [OR] 7.72, 95\% confidence interval [CI] 3.24$18.37, p<0.001$ ) and abdominal lymphadenopathy (OR 3.30, 95\% CI 1.29-8.48, $p=0.01$ ) was associated with an increased risk of pulmonary metastases. Liver metastases retained statistical significance on multivariate analysis (OR 6.17, 95\% CI 2.53-15.03, $p<0.001$ ).

Conclusion: The incidence of pulmonary metastases at the time of gastric cancer diagnosis is higher in northern Alberta than previously reported in Asian studies. Abdominal lymphadenopathy and liver metastases confer an elevated risk of pulmonary metastases.

Contexte : Les lignes directrices internationales recommandent une tomodensitométrie (TDM) thoracique de routine pour la stadification du cancer de l'estomac. Dans les pays asiatiques, où l'incidence des métastases pulmonaires est inférieure à $1 \%$, certaines lignes directrices recommandent la TMD thoracique seulement dans les cancers de la jonction gastro-œsophagienne. Si l'incidence des métastases pulmonaires est également faible au Canada, la TDM thoracique de routine pourrait ne pas être bénéfique.

Méthodes : Nous avons procédé à une analyse rétrospective des patients du Nord de l'Alberta ayant reçu un diagnostic de cancer de l'estomac entre janvier 2010 et juillet 2016. L'objectif principal de l'étude était de déterminer l'incidence des métastases pulmonaires au moment du diagnostic chez cette population. Un objectif secondaire consistait à identifier les prédicteurs potentiels des métastases pulmonaires. Les rapports de TDM ont été passés en revue pour ce qui est des métastases pulmonaires. Les données provenant des épreuves d'imagerie incluaient aussi les métastases hépatiques, la lymphadénopathie abdominale $(>1 \mathrm{~cm})$, l'ascite et les nodules épiplö̈ques ou péritonéaux. Parmi les autres données consignées, mentionnons l'âge, le sexe, de même que la localisation, le type histologique et le grade de la tumeur principale.

Résultats : Quatre cent soixante-deux patients (311 hommes, 151 femmes) ont été inclus dans l'analyse. Globalement, des métastases pulmonaires ont été observées chez 25 patients $(5,4 \%)$, et chez 11 patients sur $299(3,7 \%)$ dont le cancer principal ne se situait pas dans le cardia. À l'analyse univariée, la présence de métastases hépatiques (rapport des cotes [RC] 7,72 , intervalle de confiance [IC] de $95 \%$ de 3,24 à $18,37, p<0,001$ ) et de lymphadénopathie abdominale (RC 3,30, IC de $95 \%$, de 1,29 à $8,48, p=0,01)$ a été associée à un risque accru de métastases pulmonaires. Les métastases hépatiques ont conservé leur portée statistique lors de l'analyse multivariée (RC 6,17, IC de $95 \%$ de 2,53 à 15,03, $p<0,001$ ).

Conclusion : L'incidence des métastases pulmonaires au moment où un diagnostic de cancer de l'estomac est posé s'est révélée plus élevée dans le Nord de l'Alberta que dans les rapports d'études asiatiques précédentes. La lymphadénopathie abdominale et les métastases hépatiques confèrent un risque élevé de métastases pulmonaires. 
$\mathbf{T}$ he incidence of gastric adenocarcinoma in Canada is estimated at 8.6 per 100000 population. ${ }^{1}$ It is rare relative to other cancers in the Canadian population, and the majority of cases are diagnosed at an advanced stage. The mean 5-year survival rates for gastric cancer in the United States by clinical stage are $57 \%$ for stage I, $47 \%$ for stage IIa, 33\% for stage IIb, 26\% for stage III and $5 \%$ for stage IV. ${ }^{2}$

Lymphatic and transcoelomic metastases are common in gastric adenocarcinoma; ${ }^{2}$ however, hematogenous spread with distant metastatatic deposits in the lungs is rare. In Asian countries, where the incidence of gastric adenocarcinoma is much higher, pulmonary metastases are reported to be present in fewer than $1 \%$ of cases. ${ }^{3-5}$ In Western populations, studies from the Memorial Sloan Kettering Cancer Center in the US and Swedish registries showed higher rates of gastric adenocarcinoma with pulmonary metastases. ${ }^{6,7}$ However, these studies include recurrences and did not specify the timing of diagnosis of pulmonary metastases. The low rates of pulmonary metastases at the time of diagnosis in Eastern countries may not translate to Western populations, as there are many wellreported differences in this disease process between these population groups. These include differences in environmental exposures and treatment, as well as higher rates of proximal tumours and diffuse type histology in Western countries than in Eastern ones. ${ }^{8}$

Computed tomography (CT) of the chest is a recommended part of routine gastric adenocarcinoma staging in guidelines of the National Comprehensive Cancer Network (NCCN), the European Society for Medical Oncology (ESMO) and the European Society of Surgical Oncology (ESSO) as well as our local guidelines. ${ }^{9-11}$ Owing to the low rates of pulmonary metastases in Asian studies, particularly at the time of gastric adenocarcinoma diagnosis, 1 set of Asian guidelines that was based on expert opinion recommends that chest CT be selectively used for cases of gastroesophageal junction (GEJ) cancers, ${ }^{12}$ as GEJ cancers have shown different behaviour than non-GEJ cancers. ${ }^{7}$ The low rates of pulmonary metastases in Asian studies are, in addition to the differences noted above, in the context of gastric adenocarcinoma screening programs that lead to a higher proportion of gastric adenocarcinoma diagnoses being made at earlier stages than in Canada, where no such screening programs exist. ${ }^{8,13}$

The incidence of pulmonary metastases at the time of gastric adenocarcinoma diagnosis in the Canadian population is not well defined. Given the differences between gastric adenocarcinoma in Western and Eastern societies and the absence in Canada of screening programs such as those present in some Asian countries, the low rates of pulmonary metastases reported in Asian studies are not likely to directly translate to the Canadian population. Knowledge of the incidence of pulmonary metastases in Canada would help to define optimal staging protocols for the Canadian population. The aim of this study is primarily to define the incidence of pulmonary metastases at the time of gastric adenocarcinoma diagnosis in Alberta patients and secondarily to identify any preoperative factors that may predict higher risk for the presence of pulmonary metastases.

\section{Methods}

The Alberta Cancer Registry was reviewed retrospectively for newly diagnosed gastric adenocarcinoma cases within the Edmonton and northern Alberta zones, an area with a population of more than 1.8 million people. Cases from January 2010 to June 2016 were reviewed. The Health Research Ethics Board of the Alberta Cancer Committee approved this study. Preoperative patient demographics, tumour characteristics and imaging findings were reviewed. Patient demographics recorded included age and sex. Tumor grade and primary tumour location were coded using the International Classification of Disease, 10th Revision codes. For the purpose of the analysis, cancers coded with location in the cardia were considered to include GEJ cancers because the database codes proximal tumours as cardia and does not distinguish between cardia and GEJ. Tumour histology type in the registry is coded using SNOMED codes based on the 2015 World Health Organization classification of gastric tumours: 8490 for signet cell carcinoma, 8144 for intestinal type adenocarcinoma and 8145 for adenocarcinoma diffuse type. For the purpose of this study 8140 (adenocarcinoma, not otherwise specified) and all other subtypes were grouped together as "other." We reviewed CT scan reports for the presence of advanced abdominal disease including ascites, liver metastases, abdominal lymphadenopathy (meeting size criterion $>1 \mathrm{~cm}$ ) and omental or peritoneal nodules. Pulmonary lesions were first identified by review of chest CT scan reports. If the reporting radiologist's interpretation of the lesion was suspicious for or likely representative of metastatic disease these cases then went on to be reviewed by an expert radiologist for further analysis of these pulmonary lesions. Lymphoma, neuroendocrine and gastrointestinal stromal tumours were excluded.

Descriptive statistics were used to describe the study variables. Means and standard deviations were reported for continuous variables. Frequencies and proportions were reported for the categorical variables. Binary logistic regression was used to study the factors associated with pulmonary metastases. The univariate model included the factors by themselves with the outcome variable. The factors that were significant at the level of $p<0.10$ were entered in the multivariate model. The final multivariate model included variables or factors significant at the level of $p<0.05$ as well as confounding factors. Odds ratios (ORs) and the corresponding $95 \%$ confidence intervals (CIs) were reported. SPSS version 21 was used to 
conduct all the statistical analysis. A $p$ value $<0.05$ was used for statistical significance and 2-sided tests were used.

\section{RESULTS}

In total, 551 cases were reviewed. Thirty-eight cases of lymphoma, neuroendocrine or gastrointestinal stromal tumours were excluded, and an additional 51 cases were excluded because of missing CT chest imaging data. This left 462 cases for statistical analysis. The clinicopathologic and radiologic characteristics are shown in Table 1 and Table 2, respectively. The mean age at the time of diagnosis was 67 years. There were $311(67.3 \%)$ men and 151 $(32.7 \%)$ women. High-grade tumours were present in 250 (54.1\%) cases; 93 (20.1\%) cases were missing tumour grade data. The most common location of primary cancer was the cardia $(35.3 \%)$. There were 163 cardia and 299 noncardia cancers.

There were 38 cases with pulmonary lesions identified on initial chart screening. After review by an expert radiologist, 25 of these were deemed consistent with metastatic disease and 4 were benign in appearance. A further 6 lesions demonstrated features more consistent with primary lung carcinoma and 3 cases were called indeterminate.

Of the 25 patients with metastatic lesions, 14 had primary cancers in the cardia. For 2 of the cases deemed metastatic disease on imaging, this diagnosis was confirmed pathologically. Patients with primary cancers in the cardia were 2.44 times more likely to have pulmonary metastases

\begin{tabular}{|c|c|}
\hline Characteristic & No. $(\%)^{*}$ \\
\hline Age, yr, mean & 67 \\
\hline \multicolumn{2}{|l|}{ Sex } \\
\hline Male & 311 (67.3) \\
\hline Female & 151 (32.7) \\
\hline \multicolumn{2}{|l|}{ Tumour location } \\
\hline Cardia & 163 (35.3) \\
\hline Fundus/body & 72 (15.6) \\
\hline Antrum/pylorus & 72 (15.6) \\
\hline Lesser curve & $31(6.7)$ \\
\hline Greater curve & $16(3.5)$ \\
\hline Overlapping & $108(23.4)$ \\
\hline \multicolumn{2}{|l|}{ Tumour grade } \\
\hline Grade I/II & 119 (25.8) \\
\hline Grade III/IV & $250(54.1)$ \\
\hline Missing data & $93(20.1)$ \\
\hline \multicolumn{2}{|l|}{ Tumour histology } \\
\hline Intestinal & 89 (19.3) \\
\hline Diffuse & $44(9.5)$ \\
\hline Signet cell & $62(13.4)$ \\
\hline Other & $267(57.8)$ \\
\hline * Unless indicated oth & \\
\hline
\end{tabular}

than patients whose primary cancer was not in the cardia, although this did not reach statistical significance $(95 \% \mathrm{CI}$ $0.78-7.63, p=0.12$ ) (Table 3). Pulmonary metastases were less common in younger patients; however, this finding did not reach statistical significance (OR 0.99, 95\% CI $0.96-$ $1.02, p=0.38)$. There was also no significant effect of sex on risk for pulmonary metastases (OR $0.97,95 \%$ CI $0.41-$ $2.32, p=0.94)($ Table 3$)$.

Among all patients with newly diagnosed gastric cancer, the most common histologic subtype was other $(57.8 \%)$, followed by intestinal type (19.3\%), and $54.1 \%$ of patients had high-grade lesions. Neither tumour grade nor histologic subtype reached statistical significance in the univariate analysis (Table 3). Liver metastases (OR 7.72, 95\% CI $3.24-18.37, p<0.001)$ and abdominal lymphadenopathy (OR 3.30, 95\% CI 1.29-8.48, $p=0.01$ ) were associated with a statistically significant increased risk of pulmonary metastases (Table 3).

Table 2. Rates of radiographic detection of distant disease

in patients with newly diagnosed gastric cancer by site of metastasis

\begin{tabular}{|lc|}
\hline Site of mestastasis & No. (\%) \\
\hline Pulmonary metastases & \\
\hline Among patients with cardia cancers $(n=163)$ & $14(8.6)$ \\
\hline Among patients with noncardia cancers $(n=299)$ & $11(3.7)$ \\
\hline Advanced abdominal disease $(n=462)$ & \\
\hline Lymphadenopathy & $226(48.9)$ \\
\hline Liver metastases & $75(16.2)$ \\
\hline Ascites & $65(14.1)$ \\
\hline Omental/peritoneal disease & $31(6.7)$ \\
\hline
\end{tabular}

Table 3. Univariate analysis of preoperative variables predictive of pulmonary metastases

\begin{tabular}{|lcc|}
\hline Variable & Odds ratio $(95 \% \mathrm{Cl})$ & $p$ value \\
\hline Age $(n=462)$ & $0.99(0.96-1.02)$ & 0.38 \\
\hline Sex $(n=462)$ & $0.97(0.41-2.32)$ & 0.94 \\
\hline Tumour grade III/IV $(n=369)$ & $1.35(0.48-3.85)$ & 0.57 \\
\hline Tumour location $(n=462)$ & & 0.12 \\
\hline Cardia & $2.44(0.78-7.63)$ & 0.74 \\
\hline Fundus/body & $0.74(0.132-4.17)$ & 0.56 \\
\hline Antrum/pylorus & $1.53(0.37-6.32)$ & 0.99 \\
\hline Greater curve & 0 & 0.99 \\
\hline Lesser curve & 0 & 0.25 \\
\hline Tumour histology $(n=462)$ & $0.48(0.14-1.68)$ & 0.99 \\
\hline Intestinal & 0 & 0.68 \\
\hline Diffuse & $0.70(0.20-2.47)$ & 0.62 \\
\hline Signet cell & & $<0.001$ \\
\hline Advanced disease & $1.27(0.42-3.85)$ & 0.01 \\
\hline Ascites $(n=451)$ & $0.6(0.08-4.61)$ & \\
\hline Omental/peritoneal $(n=449)$ & $7.72(3.24-18.37)$ & $(1.29-8.48)$ \\
\hline Liver metastases $(n=453)$ & 3.30 & \\
\hline Abdominal lymphadenopathy & & \\
\hline$>1$ cm $(n=461)$ & & \\
\hline Cl $=$ confidence interval. & & \\
\hline
\end{tabular}




\begin{tabular}{|c|c|c|}
\hline Variable & $\begin{array}{c}\text { Odds ratio }(95 \% \mathrm{Cl}) \\
n=453\end{array}$ & $p$ value \\
\hline Liver metastases & $6.17(2.53-15.03)$ & $<0.001$ \\
\hline $\begin{array}{l}\text { Abdominal lymphadenopathy } \\
>1 \mathrm{~cm}\end{array}$ & $2.75(0.97-7.82)$ & 0.06 \\
\hline $\mathrm{Cl}=$ confidence interval. & & \\
\hline
\end{tabular}

On multivariate analysis, only the presence of liver metastases maintained statistical significance for predicting an increased risk of pulmonary metastases, although lymphadenopathy trended toward significance (Table 4).

\section{Discussion}

The incidence of pulmonary metastases at the time of gastric adenocarcinoma diagnosis is not well reported in the literature. In a large retrospective series looking at patients with metastatic gastric adenocarcinoma, Kong and colleagues reported an overall rate of pulmonary metastases of $0.96 \%(n=20187)$; only 66 patients $(0.3 \%)$ had pulmonary metastases at the time of diagnosis. ${ }^{3}$

To our knowledge we are the first to report the incidence of pulmonary lesions at the time of diagnosis of gastric adenocarcinoma in a Canadian population. Our rates of $5.4 \%$ overall and $3.7 \%$ in noncardia cancers are higher than previously reported. Gastric adenocarcinoma in Western populations is more likely to be located proximally and to present at an advanced stage than in populations from Eastern countries. These differences are related to dissimilarities in patient populations with respect to obesity, environmental exposures, tumour biology and the presence of screening programs in Eastern countries. ${ }^{8}$ In light of these differences our findings of higher rates of pulmonary metastases relative to previously reported numbers are not surprising.

Kong and colleagues found that pulmonary metastases were most commonly the result of (in decreasing order) hematogenous, pleural and lymphangitic spread. ${ }^{3}$ The presence of hematogenous metastasis was significantly associated with liver metastases. ${ }^{3}$ This link has been consistently reported in the literature ${ }^{3,7}$ and was confirmed in our study. At present, evidence of resection of liver metastases in the setting of gastric cancer is limited to case reports mostly from China and Japan. ${ }^{14-16}$ In these cases, the presence of pulmonary metastases, while potentially affecting prognosis, would not alter surgical decision-making.

The presence of lymphadenopathy with gastric cancer is common, with more than $80 \%$ of patients having pathologic lymph node involvement. ${ }^{17,6}$ The statistically significant increased risk of pulmonary metastases with the presence of abdominal lymphadenopathy demonstrated in this study represents a potential preoperative staging finding that could be used as part of an algorithm to select which patients should undergo chest CT scanning in preoperative staging. Proximal tumour location is associated with both locoregional and distant metastases. ${ }^{7}$ Asian guidelines have recommended that chest CT be used selectively when cancers are located at the GEJ because these malignancies show an increased propensity to spread to the chest. ${ }^{12}$ However, in our study, even though $56 \%$ of patients with pulmonary metastases had primary cardia cancers, there was no statistically significant relationship between the presence of pulmonary metastases and primary tumour location.

It is not uncommon for a patient to be referred to a surgeon with a diagnosis of gastric adenocarcinoma where a CT scan of the abdomen has been performed but not a CT scan of the chest. Two of the 25 patients with pulmonary metastases in our study had no other evidence of advanced abdominal disease on imaging. Had they not had a chest CT scan, these patients may have gone to the operating room despite having metastatic disease. Even in the setting of minimal metastatic disease, doing a resection does not provide any survival benefit over chemotherapy alone. ${ }^{18}$ This, taken together with the higher incidence of pulmonary metastases in this study relative to those previously reported, does not support selective utilization of chest CT for gastric cancer staging in the Canadian population. Although selective CT use may provide cost savings or perhaps shorten outpatient imaging wait lists, this has to be balanced with the significant risk involved in the alternative of putting a patient through an unnecessary operation. Therefore, such a strategy should be considered only after further study involving multicentre, prospective data that can identify predictive factors that can be reliably used in a staging algorithm that ensures appropriate and timely therapy for gastric cancer patients in Canada. We have established a prospective database at our centre to further study optimal staging of gastric cancer in Canada.

\section{Limitations}

The fact that our study had a relatively small sample size for studying the rare event of pulmonary metastases at the time of gastric adenocarcinoma diagnosis may help to explain why we did not find a statistically significant relationship between the presence of pulmonary metastases and primary tumour location. In addition, the retrospective database we used in our study does not differentiate lesions in the cardia from those truly at the GEJ, which could have affected our results. In larger series, GEJ tumours were more likely to metastasize to the lungs. ${ }^{7}$ The other major limitation of this study also relates to its retrospective design, particularly regarding limited access to data. For a large number of cases $(20.1 \%)$, tumour grade 
was not identified. Similarly, there were very few chest $\mathrm{x}$-rays available for comparison with CT findings. This limits the conclusions that can be drawn regarding the utility of chest $\mathrm{x}$-ray as a staging tool. Positron emission tomography (PET)/CT has been suggested to identify additional distant metastases $;{ }^{19}$ however, PET/CT data were not collected as this modality is only used routinely for esophageal tumours in our centre. As a result there could have been additional metastases that were not picked up. Furthermore, pulmonary lesions were identified on the basis of imaging done at the time of diagnosis, without the benefit of long-term follow-up data. Only 2 (8\%) of the metastatic lesions were confirmed pathologically. Many small lesions that lack definitive features are picked up on CT scans that in the absence of follow-up data may or may not represent metastatic disease. Additionally, the patient's smoking status was not recorded in this retrospective chart review. Although some lesions showed characteristics of primary pulmonary carcinoma, it is possible, with smoking being a risk factor for both gastric and primary lung cancer, ${ }^{20}$ that some of these small pulmonary lesions may still in fact represent primary pulmonary malignancy. A primary lung cancer can occur in $0.5 \%$ to $1.7 \%$ of patients with gastric adenocarcinoma, ${ }^{3}$ which is consistent with our findings $(1.3 \%)$. Thus, the lack of follow-up data for small or indeterminate lesions may limit the accuracy of the reported incidence of pulmonary metastases at the time of gastric adenocarcinoma diagnosis in this study. From a technical standpoint, staging CT scans were performed in multiple centres, where the use of different scanners and/or protocols may also alter the rates of pulmonary lesions reported.

\section{Conclusion}

The incidence of pulmonary lesions in the Edmonton and northern Alberta zones at the time of gastric adenocarcinoma diagnosis was $5.4 \%$ overall and $3.7 \%$ in noncardia cancers. This result is higher than previously reported and therefore supports continued use of routine chest CT scanning in the staging of gastric cancer cases in Canada. In the current study, abdominal lymphadenopathy and liver metastases were identified as predictors of pulmonary metastases.

Affiliations: From the Department of Surgery, University of Alberta, Edmonton, Alta. (Nostedt, McCall, Schiller); the Faculty of Medicine and Dentistry, University of Alberta, Edmonton, Alta. (Gibson-Brokop); the Department of Medical Oncology and the Department of Mathematical and Statistical Sciences, University of Alberta, Edmonton, Alta. (Ghosh); and the Department of Radiology and Diagnostic Imaging, University of Alberta, Edmonton, Alta. (Seidler).

Competing interests: None declared.

Contributors: M. McCall and D. Schiller designed the study. J. Nostedt, L. Gibson-Brokop and D. Schiller acquired the data, which J. Nostedt, S. Ghosh and M. Seidler analyzed. J. Nostedt wrote the article, which all authors critically reviewed. All authors approved the final version to be published.

\section{References}

1. Canadian Cancer Society's Advisory Committee on Cancer Statistics. Canadian cancer statistics 2017. Toronto, ON: Canadian Cancer Society; 2017.

2. In H, Ravetch E, Langdon-Embry $M$, et al. The newly proposed clinical and post-neoadjuvant treatment staging classifications for gastric adenocarcinoma for the American Joint Committee on Cancer (AJCC) staging. Gastric Cancer 2018;21:1-9.

3. Kong JH, Lee J, Yi CA, et al. Lung metastases in metastatic gastric cancer: pattern of lung metastases and clinical outcome. Gastric Cancer 2012;15:292-8.

4. Koga S, Takebayashi M, Kaibara N, et al. Pathological characteristics of gastric cancer that develop hematogenous recurrence, with special reference to the site of recurrence. 7 Surg Oncol 1987;36: 239-42.

5. Kanemitsu Y, Kondo H, Katai H, et al. Surgical resection of pulmonary metastases from gastric cancer. 7 Surg Oncol 1998;69:147-50.

6. D'Angelica M, Gonen M, Brennan MF, et al. Patterns of initial recurrence in completely resected gastric adenocarcinoma. Ann Surg 2004;240:808-16.

7. Riihimaki M, Hemminki A, Sundquist K, et al. Metastatic spread in patients with gastric cancer. Oncotarget 2016;7:52307-16.

8. Bickenbach K, Strong VE. Comparisons of gastric cancer treatments: east vs. west. $\mathcal{F}$ Gastric Cancer 2012;12:55-62.

9. Waddell T, Verheij M, Allum W, et al. Gastric cancer: ESMOESSO-ESTRO clinical practice guidelines for diagnosis, treatment and follow-up. Ann Oncol 2013;24(Suppl 6):vi57-63.

10. National Comprehensive Cancer Network. Gastric cancer version I;2018. Available: www.nccn.org/professionals/physician_gls/pdf/ gastric.pdf (accessed 13 Apr. 2018).

11. Alberta Health Services. Gastric cancer: clinical practice guideline GI-008 version 4. Edmonton: Alberta Health Services; 2016. Available: www.albertahealthservices.ca/assets/info/hp/cancer/if -hp-cancer-guide-gi008-gastric.pdf (accessed 16 Apr. 2019).

12. Shen L, Shan YS, Hu HM, et al. Management of gastric cancer in Asia: resource-stratified guidelines. Lancet Oncol 2013;14:e 535-47.

13. Hamashima C; Systematic Review Group and Guideline Development Group for Gastric Cancer Screening Guidelines. Update version of the Japanese guidelines for gastric cancer screening. Ipn 7 Clin Oncol 2018;48:673-83.

14. Song A, Zhang X, Yu F, et al. Surgical resection for hepatic metastasis from gastric cancer: a multi-institution study. Oncotarget 2017;8: 71147-53.

15. Ryu T, Takami Y, Wada Y, et al. Oncological outcomes after hepatic resection and/or surgical microwave ablation for liver metastasis from gastric cancer. Asian 7 Surg 2017;42:100-45.

16. Namikawa T, Kawanishi Y, Fujieda Y, et al. A case of advanced gastric cancer with liver metastasis treated by curative surgery after chemotherapy using S-1 plus oxaliplatin. Gan To Kagaku Ryobo 2017;44:1446-8.

17. Dicken BJ, Saunders LD, Jhangri GS, et al. Gastric cancer: establishing predictors of biologic behavior with use of population-based data. Ann Surg Oncol 2004;11:629-35.

18. Fujitani K, Yang HK, Mizusawa J, et al. Gastrectomy plus chemotherapy versus chemotherapy alone for advanced gastric cancer with a single non-curable factor (REGATTA): a phase 3, randomised controlled trial. Lancet Oncol 2016;17:309-18.

19. Findlay JM, Antonowicz S, Segaran A, et al. Routinely staging gastric cancer with (18)F-FDG PET-CT detects additional metastases and predicts early recurrence and death after surgery. Eur Radiol 2019;29:2490-8.

20. IARC Working Group on the Evaluation of Carcinogenic Risks to Humans. Tobacco smoke and involuntary smoking. IARC Monogr Eval Carcinog Risks Hum 2004;831-1438. 